\title{
L-lactic acid production by Aspergillus brasiliensis overexpressing the heterologous Idha gene from Rhizopus oryzae
}

\author{
Nadège Liaud ${ }^{1,2,3}$, Marie-Noëlle Rosso ${ }^{1}$, Nicolas Fabre ${ }^{3}$, Sylvaine Crapart ${ }^{3}$, Isabelle Herpoël-Gimbert ${ }^{1,2}$, \\ Jean-Claude Sigoillot ${ }^{1,2}$, Sana Raouche ${ }^{1,2}$ and Anthony Levasseur ${ }^{4^{*}}$
}

\begin{abstract}
Background: Lactic acid is the building block of poly-lactic acid (PLA), a biopolymer that could be set to replace petroleum-based plastics. To make lactic acid production cost-effective, the production process should be carried out at low pH, in low-nutrient media, and with a low-cost carbon source. Yeasts have been engineered to produce high levels of lactic acid at low pH from glucose but not from carbohydrate polymers (e.g. cellulose, hemicellulose, starch). Aspergilli are versatile microbial cell factories able to naturally produce large amounts of organic acids at low $\mathrm{pH}$ and to metabolize cheap abundant carbon sources such as plant biomass. However, they have never been used for lactic acid production.
\end{abstract}

Results: To investigate the feasibility of lactic acid production with Aspergillus, the NAD-dependent lactate dehydrogenase ( $\mathrm{LDH}$ ) responsible for lactic acid production by Rhizopus oryzae was produced in Aspergillus brasiliensis BRFM103. Among transformants, the best lactic acid producer, A. brasiliensis BRFM1877, integrated 6 IdhA gene copies, and intracellular LDH activity was $9.2 \times 10^{-2} \mathrm{U} / \mathrm{mg}$. At a final $\mathrm{pH}$ of 1.6, lactic acid titer reached $13.1 \mathrm{~g} / \mathrm{L}$ (conversion yield: $26 \% \mathrm{w} / \mathrm{w}$ ) at $138 \mathrm{~h}$ in glucose-ammonium medium. This extreme $\mathrm{pH}$ drop was subsequently prevented by switching nitrogen source from ammonium sulfate to Na-nitrate, leading to a final $\mathrm{pH}$ of 3 and a lactic acid titer of $17.7 \mathrm{~g} / \mathrm{L}$ (conversion yield: 47\%, w/w) at $90 \mathrm{~h}$ of culture. Final titer was further improved to $32.2 \mathrm{~g} / \mathrm{L}$ of lactic acid (conversion yield: 44\%, w/w) by adding $20 \mathrm{~g} / \mathrm{L}$ glucose to the culture medium at $96 \mathrm{~h}$. This strain was ultimately able to produce lactic acid from xylose, arabinose, starch and xylan.

Conclusion: We obtained the first Aspergillus strains able to produce large amounts of lactic acid by inserting recombinant IdhA genes from $R$. oryzae into a wild-type $A$. brasiliensis strain. $\mathrm{pH}$ regulation failed to significantly increase lactic acid production, but switching nitrogen source and changing culture feed enabled a 1.8-fold increase in conversion yields. The strain produced lactic acid from plant biomass. Our findings make A. brasiliensis a strong contender microorganism for low-pH acid production from various complex substrates, especially hemicellulose.

\section{Background}

Lactic acid (LA) is a colorless, odorless monocarboxylic acid naturally produced by many organisms. This weak acid has low buffering power and is tasteless, and has thus found broad use as an excipient in the food, cosmetics, pharmaceutical and chemical industries [1,2]. LA

\footnotetext{
* Correspondence: anthony.levasseur@univ-amu.fr

${ }^{4}$ Aix-Marseille Université, Unité de Recherche sur les Maladies Infectieuses et Tropicales Emergentes (URMITE), UM63, CNRS 7278, IRD 198, INSERM U1095, IHU Méditerranée Infection, Pôle des Maladies Infectieuses, Assistance Publique-Hôpitaux de Marseille, Faculté de Médecine, 27 Bd Jean Moulin, 13005 Marseille, France

Full list of author information is available at the end of the article
}

is listed in the GRAS inventory, the L-isomer being preferred for food and pharmaceutical applications due to the prevalence of the L-LA found in mammals [3]. Estimates from 2008 claim the food industry absorbs up $85 \%$ of LA production [1]. Besides its application as an additive or excipient, LA is the building block for polylactic acid (PLA), a biodegradable polymer that could be set to replace petroleum-based plastics. With mounting environmental pressure for sustainable industry, demand for PLA biomaterial is increasing demand for LA, for which the market is expected to hit 1 million tons by 2020 [4]. Nevertheless, the selling price of PLA still has 
to be cut by at least $50 \%$ to compete with fossil fuelbased plastics [2].

Industrial LA production bioprocesses traditionally use lactic acid bacteria (LAB), mainly from Lactobacillus species. LA is a natural end-product of carbohydrate metabolism and is produced from pyruvate with an NAD-dependent lactic acid dehydrogenase (LDH). LAB naturally produce high amounts of LA by fermentation, and yields can approach the theoretical maximum of $100 \%(\mathrm{w} / \mathrm{w})$ for homolactic fermentation in complex media $[1,3,5,6]$. However, LA production by LAB is expensive due to their complex nutrient requirements and the restrictive use of $\mathrm{pH}$ neutralizers (e.g. $\mathrm{CaCO}_{3}$ ) during fermentation [5]. To decrease LA production costs and expand the market for LA and its green derivatives, lowcost media containing cheap carbon sources and low-pH production processes are needed [2]. Low-pH production processes that do not require neutralizing chemicals allow undissociated (free) LA to be recovered directly from the broth without any acidification step in the purification process [1].

Members of the fungal kingdom known to have low nutrient requirements and to be acid-tolerant are considered an attractive solution for low-pH LA production. Research into genetically-modified yeasts expressing heterologous $l d h$ genes has intensified, and efficient low$\mathrm{pH}$ production of LA has been obtained in yeasts from Saccharomyces [7-11], Kluyveromyces [12] and Candida genera [13-15]. This engineered yeast-based strategy has reached industrial application, and L-LA is currently produced from fermentable sugars released from pretreated corn starch, sugarcane or sugar beet [2].

Direct conversion of starch or cheaper carbon sources such as raw plant biomass would further reduce the costs of L-LA production. Using lignocellulose as carbon source entails enzymatic depolymerization of cellulose and hemicelluloses followed by assimilation of the released monomers, mainly glucose, xylose and associated arabinose [16]. S. cerevisiae does not naturally assimilate pentose sugars [17]. However, Pichia stipitis and Candida sonorensis are able to naturally utilize xylose, and both strains were successfully engineered for L-LA production from xylose $[15,18]$. Yeasts do not feature among natural lignocellulose degraders due to their poor (hemi)cellulolytic enzyme arsenal. Therefore, yeast utilization requires complex metabolic engineering before this objective is achievable [19]. In contrast, wood-degrading and saprophytic fungi such as filamentous fungi can grow on various carbon sources and are able to produce the enzymes necessary for biomass breakdown [20].

The sole filamentous fungus known to produce large amounts of L-LA from various carbohydrate materials is Rhizopus oryzae, which belongs to the order Mucorales $[21,22]$. This fungus is naturally able to produce L-LA from glucose with yields reaching about $80 \%(\mathrm{w} / \mathrm{w})$ in minimum medium [23-25]. Attempts to produce L-LA from xylose $[26,27]$ and low-cost carbon sources such as raw starch [25], wheat straw [28] and cellulose [29] have already been successfully performed [23], but L-LA production using Rhizopus still requires near-neutral $\mathrm{pH}$ conditions, which heavily compromises the global process [21-24]. To our knowledge, no other filamentous fungus has been studied for L-LA production. Aspergillus is a very powerful microbial cell factory that has been used for decades to produce organic acids such as citric acid ( $A$. niger) and itaconic acid (A. itaconicus and $A$. terreus) at low $\mathrm{pH}$ and at industrial scales [24]. This low-pH organic acid production suggests that Aspergilli are able to endure the weak acid stress caused by organic acid accumulation, which makes them promising candidates for low-pH L-LA production. Furthermore, Aspergilli secrete diverse hydrolytic and oxidative enzymes involved in the breakdown of complex carbohydrates [30] and are able to metabolize pentoses from plant biomass degradation. This ability could enable L-LA production from plant biomass, thus cutting down the cost of carbon source.

The aim of this study was to investigate whether Aspergillus brasiliensis could be an efficient alternative to yeast for L-LA production at low $\mathrm{pH}$. A. brasiliensis, a species from the Nigri section of Aspergillus [31], has been suggested to be safer for industrial utilization than A. niger since it is unable to produce fuminosin and ochratoxins, which are carcinogenic mycotoxins [32]. In particular, A. brasiliensis strain BRFM103 is able to accumulate more ethanol than strains from other Aspergillus species in minimum medium without $\mathrm{pH}$ regulation [33]. Both lactic acid and ethanol are produced from pyruvate, in the cytosol, with the regeneration of $\mathrm{NAD}^{+}$ cofactors. Lactic acid fermentation will provide an alternative route for the regeneration of $\mathrm{NAD}^{+}$, potentially replacing ethanol production. L-LA-producing strains of A. brasiliensis were obtained by multicopy integration of the heterologous $l d h A$ gene from $R$. oryzae. Gene copy number and subsequent LDH intracellular activity were determined in order to study their impact on L-LA production yields. The impact of $\mathrm{pH}$ on L-LA production was investigated with the strain showing the highest intracellular LDH activity. Finally, L-LA production was tested with various carbohydrate substrates.

\section{Results and Discussion}

\section{Selection of transformants in ammonium medium} without $\mathrm{pH}$ regulation

After co-transformation of A. brasiliensis BRFM103 with the lactate dehydrogenase A gene $(l d h A)$ and the hygromycin resistance gene $(h p h+)$, isolated transformants were screened for L-LA production in MM1 liquid medium without $\mathrm{pH}$ regulation. $\mathrm{pH}$ of the medium 
dropped from 5 to 2.5 in $40 \mathrm{~h}$ then slowly decreased to a final $\mathrm{pH}$ of 1.6 at $138 \mathrm{~h}$ culture. Eight transformants produced L-LA and were selected for further analysis. The supernatants of these clones were analyzed by chromatography to determine residual glucose, L-LA and by-product concentrations. At $138 \mathrm{~h}$ incubation, all the glucose was consumed. L-LA production at $138 \mathrm{~h}$ incubation was low $(0.03$ to $0.6 \mathrm{~g} / \mathrm{L})$ for three of the $\mathrm{L}$ LA-producing transformants (BRFM1879, BRFM1873, and BRFM1881). Five recombinant strains (BRFM1872, BRFM1874, BRFM1875, BRFM1877 and BRFM1880) demonstrated high L-LA production (11.7 to $13.9 \mathrm{~g} / \mathrm{L}$ ) from $50 \mathrm{~g} / \mathrm{L}$ of glucose at $138 \mathrm{~h}$ of culture. L-LA conversion yields ranged from $0.1 \%(\mathrm{w} / \mathrm{w})$ for BRFM1879 to $27 \%(\mathrm{w} / \mathrm{w})$ for BRFM1880 (Figure 1). Recombinant strains produced low ethanol conversion yields ranging from 1 to $14 \%(\mathrm{w} / \mathrm{w})$. For the transformants exhibiting L-LA conversion yields higher than $23 \%(w / w)$, ethanol production was nearly abolished with final conversion yields below $1 \%(\mathrm{w} / \mathrm{w})$, suggesting that the heterologous ldhA efficiently compete with native pyruvate decarboxylase (PDC) for pyruvate utilization in high L-LAproducing strains. Similar results were obtained in yeasts with native ethanol production such as Candida sonorensis, where the natural production of around $20 \mathrm{~g} / \mathrm{L}$ of ethanol was nearly abolished by $l d h$ insertion in neutralized culture conditions [13]. In S. cerevisiae, which naturally produces larger amounts of ethanol, additional modifications of the ethanol pathway are necessary to abolish ethanol production [34,35]. L-LA production had no severe impact on growth of the recombinant strains. However, the biomass conversion yields of high L-LA-producing strains, at 22 to $24 \%$ $(w / w)$, were lower than the biomass conversion yields of low L-LA-producing strains, at 28 to $31 \%$ (w/w) (Figure 1).

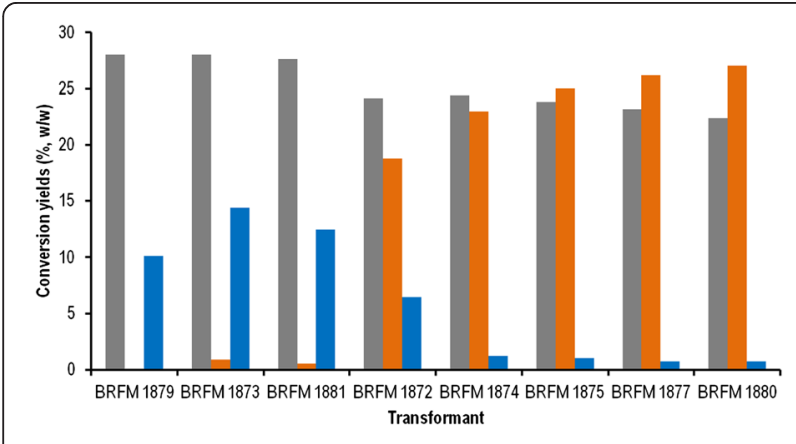

Figure 1 Conversion yields of glucose to biomass, lactic acid, and ethanol by the L-LA-producing transformants of A. brasiliensis. Conversion yields of lactic acid at $138 \mathrm{~h}$ of culture (orange square), ethanol at $138 \mathrm{~h}$ of culture (blue square), and dry biomass at $144 \mathrm{~h}$ of culture (gray square), are expressed in g/100 $\mathrm{g}$ of glucose consumed. Transformant strains are sorted on the basis of their L-LA conversion yields.

\section{Gene copy number and intracellular LDH activity in recombinant strains}

ldhA gene copy number and intracellular NADH dehydrogenase activities were determined for the recombinant $A$. brasiliensis-ldhA strains. Fresh cultures of $A$. brasiliensis-ldhA transformants in MM2 liquid medium without $\mathrm{pH}$ regulation were used for these experiments. The wild-type BRFM103 strain was studied as a control.

The genome of LA-producing strains contained between 3 and $16 l d h A$ gene copies (Figure 2A). Intracellular LDH activities increased with $l d h A$ gene copy number up to 6 copies, corresponding to a maximum LDH activity of $9.1 \times 10^{-2} \mathrm{U} / \mathrm{mg}$ (Figure 2A). Above $6 \mathrm{ldh} A$ gene copies, LDH activity decreased gradually to a minimal value of $1.4 \times 10^{-2} \mathrm{U} / \mathrm{mg}$. The reduced LDH activity could be a consequence of $l d h A$ mRNA degradation due to gene silencing occurring in Aspergillus [36]. Furthermore, some transformants with equal gene copy numbers showed variable LDH activity levels, probably as a result of ectopic integration of the $l d h A$ gene, which is a feature of the transformation system [37]. Indeed, expression level can be different in different regions of the genome.

Increasing LDH activity had a positive impact on LA yields up to $6.7 \times 10^{-2} \mathrm{U} / \mathrm{mg}$ (Figure $2 \mathrm{~B}$ ). Above this threshold, there was no further observable increase in yield. This suggests that the LDH activity is not a limiting step in lactic acid production above $6.7 \times 10^{-2} \mathrm{U} / \mathrm{mg}$, and so another parameter, such as medium composition or LA toxicity, might be limiting LA production. Since high LDH activity is likely to empower LDH in the competition for pyruvate utilization, A. niger BRFM1877, showing the highest intracellular LDH activity, was chosen for further investigation.

\section{Impact of $\mathrm{pH}$ on L-LA production by A. brasiliensis BRFM1877}

Over the course of liquid culture of BRFM1877 in MM1, $\mathrm{pH}$ of the medium dropped from 5 to 2.4 in $40 \mathrm{~h}$ then slowly decreased to a final value of 1.6 at $138 \mathrm{~h}$ of culture. This intense acidification illustrates the acid tolerance of Aspergilli. For citric acid production, a $\mathrm{pH}$ of 2 increases production yield [38]. However, at low external $\mathrm{pH}$, more energy is needed for the export of lactate, since undissociated L-LA from the broth can freely reenter the cell. This is suggested to be the main reason for weak acid stress in yeasts $[11,13]$. In order to evaluate the impact of $\mathrm{pH}$ acidification during L-LA production by BRFM1877, the strain was cultured in MM2 liquid medium ( $50 \mathrm{~g} / \mathrm{L}$ glucose initial) containing Na-nitrate as nitrogen source instead of ammonium sulfate. In this experiment, extra glucose $(20 \mathrm{~g} / \mathrm{L})$ was added at $96 \mathrm{~h}$ growth to increase final titers.

With Na-nitrate as nitrogen source, $\mathrm{pH}$ dropped from 5 to 3.2 in 48 hours then remained unchanged during 

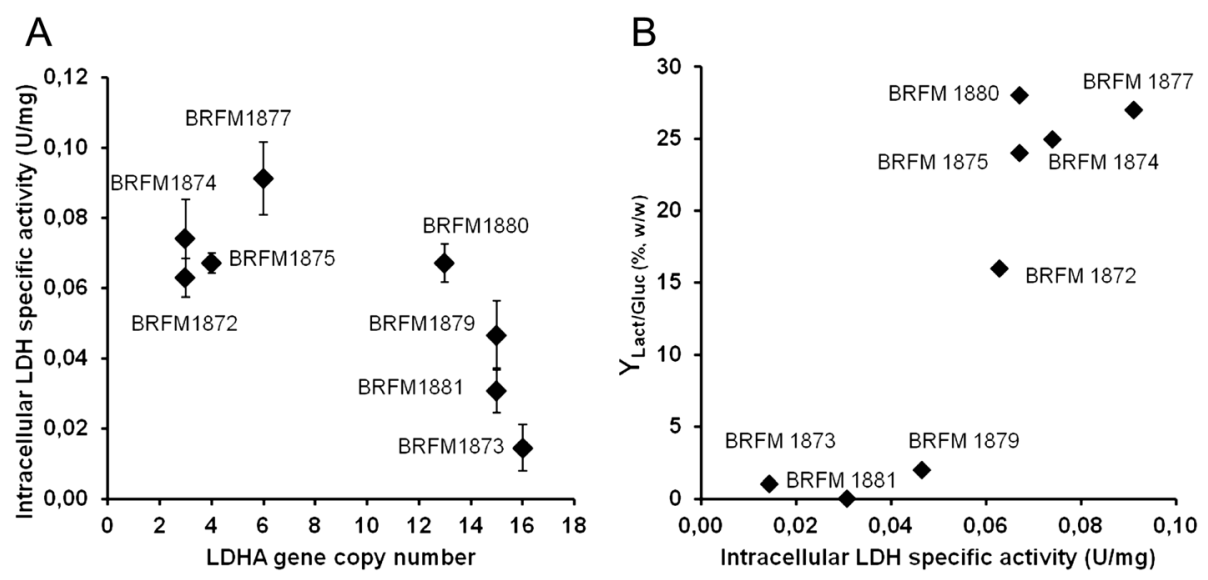

Figure 2 Relation between intracellular LDH activity and gene copy number (A) or lactic acid conversion yields (B). The gene copy number was determined with fresh $24 \mathrm{~h}$ cultures. Activities are expressed in $\mathrm{U}$ per $\mathrm{mg}$ of total proteins, where $1 \mathrm{U}$ is the amount of $\mu$ mole $\mathrm{NADH}, \mathrm{H}^{+}$reduced by intracellular extract per min. For intracellular LDH activity, measurements were carried out in triplicate at $72 \mathrm{~h}$ of culture; error bars show the standard deviation. Conversion yields were measured during the screening assays at $138 \mathrm{~h}$ incubation.

further culture. The L-LA titers and conversion yields reached mean values of $17.7 \mathrm{~g} / \mathrm{L}$ and $32.2 \mathrm{~g} / \mathrm{L}, 47 \%(\mathrm{w} / \mathrm{w})$ and $44 \%(\mathrm{w} / \mathrm{w})$, at $90 \mathrm{~h}$ (before extra glucose addition) and $260 \mathrm{~h}$ of culture, respectively (Figure 3A). These titers and yields are higher than those obtained at $\mathrm{pH}$ below 2 $(13.1 \mathrm{~g} / \mathrm{L}, 26 \%, \mathrm{w} / \mathrm{w})$, highlighting that ammonium sulfate as a nitrogen source restricted L-LA production, most probably via strong $\mathrm{pH}$ acidification. Na-nitrate was therefore used as nitrogen source to further investigate the impact of $\mathrm{pH}$ on L-LA production by A. brasiliensis BRFM1877.

Cultures at near-neutral $\mathrm{pH}$ were performed in MM2 liquid medium with $\mathrm{CaCO}_{3}$ addition and extra glucose addition at $96 \mathrm{~h} . \mathrm{CaCO}_{3}$ was added after spore germination $(24 \mathrm{~h})$ at a final concentration of $80 \mathrm{~g} / \mathrm{L}$. Immediately after $\mathrm{CaCO}_{3}$ addition, $\mathrm{pH}$ increased from 4.0 to 6.5 and stabilized around 7.5 within a few hours and throughout subsequent fungal growth. L-LA productivity was strongly
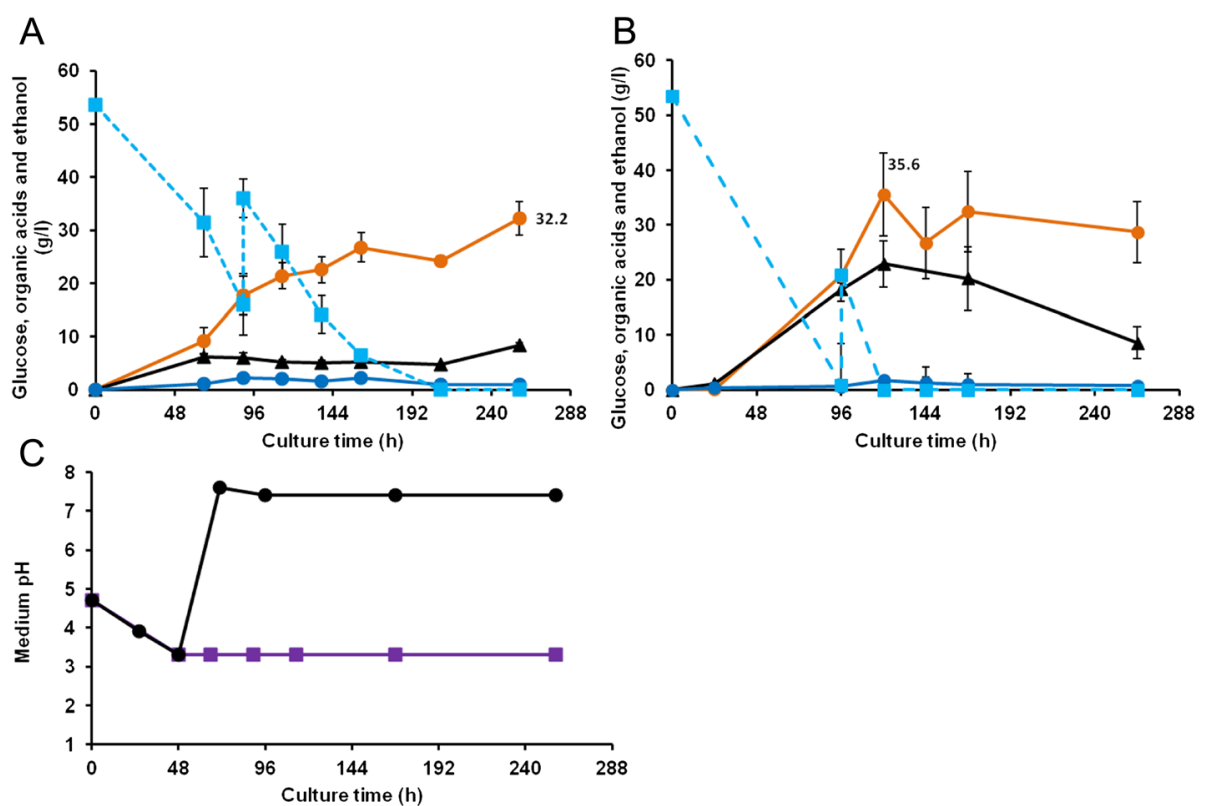

Figure 3 Impact of pH on organic acid production by A. brasiliensis BRFM1877 in glucose-nitrate-containing medium. Glucose (blue square), gluconic acid (black triangle), ethanol (blue circle), and lactic acid (orange circle) concentrations in cultures carried out in MM2 liquid medium started with $50 \mathrm{~g} / \mathrm{L}$ of glucose then added with $20 \mathrm{~g} / \mathrm{L}$ of glucose at $96 \mathrm{~h}$ of culture, without (A) and with (B) addition of $80 \mathrm{~g} / \mathrm{L} \mathrm{CaCO}$ after $24 \mathrm{~h}$ of culture. The evolution of $\mathrm{pH}$ in both cultures, with (black triangle) and without (violet square) $\mathrm{CaCO} 3$ addition, is also presented (C). Experiments were carried out in triplicate. Error bars show standard deviations. 
improved from $0.13 \mathrm{~g} /$ (L.h) to $0.32 \mathrm{~g} /(\mathrm{L} . \mathrm{h})$ by $\mathrm{pH}$ neutralization (Figure 3). Furthermore, the L-LA titers reached mean values of $20.8 \mathrm{~g} / \mathrm{L}$ and $35.6 \mathrm{~g} / \mathrm{L}$ at $96 \mathrm{~h}$ (before extra glucose addition) and $120 \mathrm{~h}$ of culture, respectively (Figure 3B). The conversion yields from $70 \mathrm{~g} / \mathrm{L}$ of glucose were therefore $51 \%(\mathrm{w} / \mathrm{w})$ and $46 \%(\mathrm{w} / \mathrm{w})$ with and without $\mathrm{CaCO}_{3}$ addition, respectively. This result shows that adding $\mathrm{CaCO}_{3}$ has a small effect on L-LA titers and conversion yields of $A$. brasiliensis BRFM1877 in the conditions tested. Moreover, cultures at $\mathrm{pH}$ above the $\mathrm{pKa}$ of lactic acid (3.8) led to the production of calcium lactate and complicate the recovery of free lactic acid [2]. Therefore, concentration of free lactic acid will be higher in culture at $\mathrm{pH} 3$ than culture at $\mathrm{pH} 7.5$ (with $\mathrm{CaCO}_{3}$ addition).

The low effect of $\mathrm{pH}$ neutralization on L-LA titers and conversion yields could be explained by the significant increase of gluconic acid. The titer of gluconic acid obtained in neutralized conditions was $22.9 \mathrm{~g} / \mathrm{L}$ whereas only $6.2 \mathrm{~g} / \mathrm{L}$ was produced at $\mathrm{pH} 3$. Glucose oxidase, the enzyme responsible for gluconic acid production, is known to be less efficient at a pH below 3 [38]. Therefore, the slight positive effect of $\mathrm{pH}$ neutralization on lactic acid production might be attenuated by the negative effect of gluconic acid production. One additional advantage of culturing A. brasiliensis BRFM1877 at pH 3 is that it reduces the production of gluconic acid without genetic modification of the gluconic acid metabolic pathway. Studies on recombinant yeast strains expressing heterologous $l d h$ genes have reported various effects of $\mathrm{pH}$ on L-LA production $[7,13,39,40]$, the most prevalent being the effect of host genetic background and origin of the heterologous LDHA on low pH L-LA production [13,41]. Looking at the recombinant yeasts expressing the same $l d h$ gene from $R$. oryzae, A. brasiliensis BRFM1877 compares favorably for low-pH L-LA production. For instance, the production yield of $S$. cerevisiae cultivated at $\mathrm{pH} 3.5$ was $32 \%(29.2 \mathrm{~g} / \mathrm{L}$ of L-LA from $92 \mathrm{~g} / \mathrm{L}$ of glucose) [40] whereas C. sonorensis cultivated without $\mathrm{pH}$ regulation produced $12 \%$ of L-LA $(6 \mathrm{~g} / \mathrm{L}$ from $50 \mathrm{~g} / \mathrm{L}$ of glucose) [13]. Here, L-LA yielded $44 \%(32.2 \mathrm{~g} / \mathrm{L}$ of L-LA from $70 \mathrm{~g} / \mathrm{L}$ of glucose) in nitrate minimum medium at $\mathrm{pH} 3$, demonstrating that $A$. brasiliensis BRFM1877 shows promising performances for L-LA production at low $\mathrm{pH}$.

\section{Production of lactic acid from various substrates by $A$. brasiliensis BRFM1877}

In agreement with the versatile ability of Aspergilli to break down the lignocellulose building blocks, we evaluated the ability of $A$. brasiliensis BRFM1877 to assimilate the main pentose monomers from hemicelluloses, i.e. Dxylose and associated L-arabinose, compared to the main hexose, D-glucose, in MM2 liquid medium without $\mathrm{pH}$ neutralization. As expected from the literature [15], the best L-LA production yield $(34 \%, \mathrm{w} / \mathrm{w})$ was obtained from D-glucose (Figure 4A). D-xylose was also an efficient carbon source, at $24 \%(\mathrm{w} / \mathrm{w})$ L-LA production yield (Figure 4B). Using L-arabinose, production yield was $18 \% \mathrm{w} / \mathrm{w}$ (Figure $4 \mathrm{C}$ ). A similar decrease in product formation when pentoses are used instead of glucose is reported for ethanol production by yeasts. [42]. A redox imbalance due to the need for NADPH in the reduction step of xylose degradation is proposed to be responsible for this decreased production [42]. In Aspergillus, Dxylose and L-arabinose degradation also use NADPH. Moreover, L-arabinose has a greater need for NADPH than D-xylose [43]. Similar redox imbalance could explain the lower L-LA yield observed with L-arabinose compared to D-xylose. The maximum concentration of L-LA $(18.5 \mathrm{~g} / \mathrm{L})$ was obtained at $120 \mathrm{~h}$ culture from Dglucose (Figure 4A). Production time was extended by using pentoses. The strain produced maximal titers of $12.3 \mathrm{~g} / \mathrm{L} \mathrm{L}$-LA at $216 \mathrm{~h}$ from D-xylose (Figure 4B) and $9.0 \mathrm{~g} / \mathrm{L}$ at $264 \mathrm{~h}$ from L-arabinose (Figure $4 \mathrm{C}$ ). The various production timescales could be explained by the lag phase due to adaptation of the strain transferred from Sabouraud broth (glucose) to media containing pentoses as carbon sources. Alternatively, fungal growth could be slowed down by its xylose and arabinose uptake rates [17].

Since A. brasiliensis BRFM1877 was able to produce LLA from glucose and xylose, we investigated its ability to directly convert glucose and xylose-based polymers, i.e. potato starch and birchwood xylan. L-LA titers reached $11.7 \mathrm{~g} / \mathrm{L}$ at $120 \mathrm{~h}$ and $8.6 \mathrm{~g} / \mathrm{L}$ at $168 \mathrm{~h}$ of cultivation from starch and xylan, respectively (Figure 4D). Production yields were $23 \%(\mathrm{w} / \mathrm{w})$ from starch and $17 \%(\mathrm{w} / \mathrm{w})$ from xylan. The loss of yield on these polymers compared to the production yields of their corresponding monomers (glucose $34 \%, \mathrm{w} / \mathrm{w}$; xylose $24 \%, \mathrm{w} / \mathrm{w}$ ) could be attributed to the extra energy needed for the production of starch or xylan-degrading enzymes. Alternatively, L-LA production could be impacted by an incomplete degradation of the polymers. Interestingly, there was no significant lag in LLA production times on polymers compared with their corresponding monomers. Indeed, the maximum L-LA titers were obtained at $120 \mathrm{~h}$ from glucose- and starchcontaining media. Surprisingly, our results even suggest that xylan was consumed faster than xylose. Note that we used the same preculture to inoculate all the flasks in this experiment. This result suggests that degradation of the polymer was not a limiting step for L-LA production from starch and xylan.

The major bottleneck for cost-efficient metabolite production from polymers is the cost of enzymatic pretreatment of raw materials [23]. Here, the production of L-LA directly from starch and xylan, without addition of enzyme cocktail, emerges as a novel and promising biotechnological method for L-LA production. 


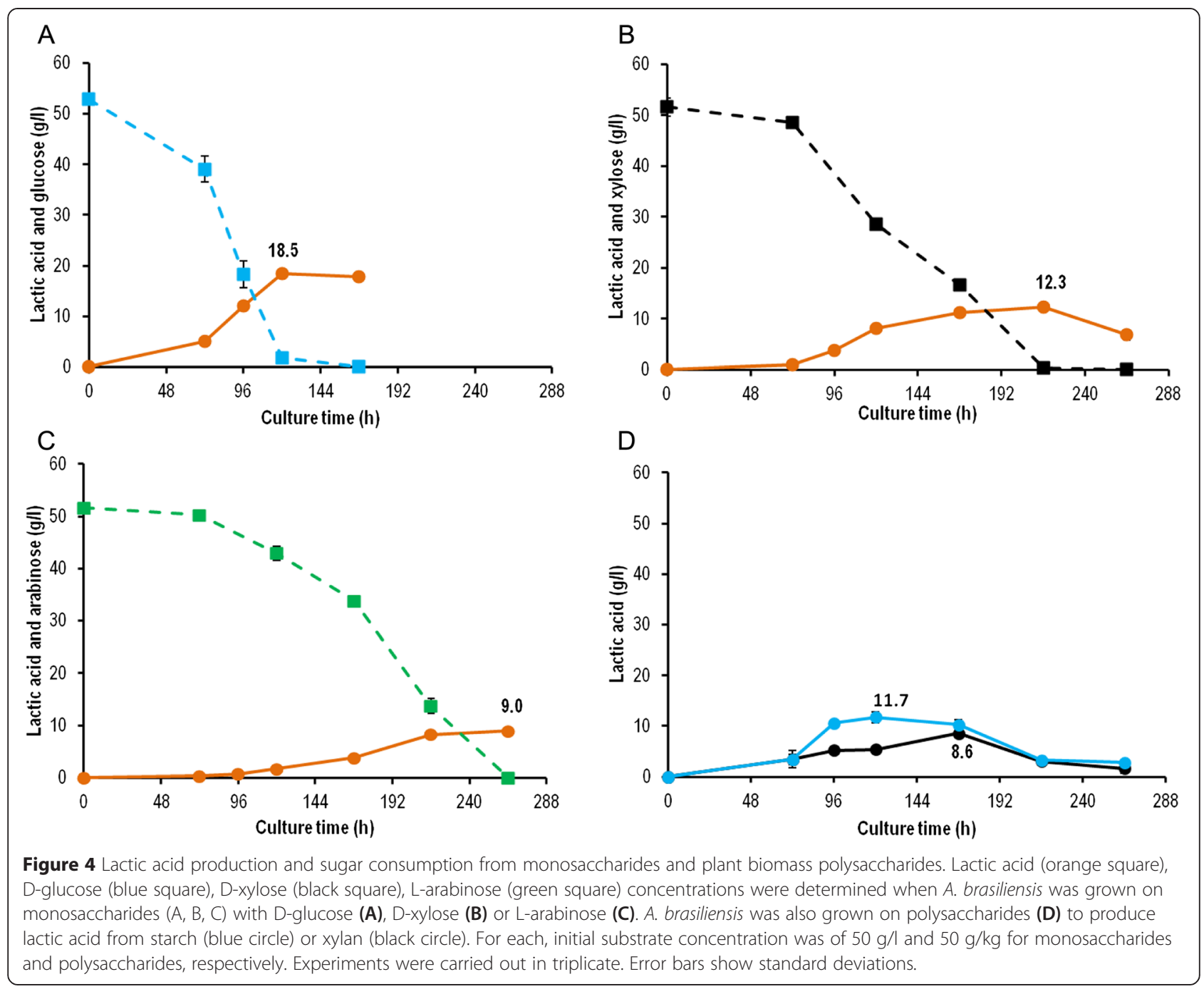

\section{Conclusion}

The overexpression of a heterologous $l d h A$ gene from $R$. oryzae made it possible to produce significant amounts of L-LA by $A$. brasiliensis recombinant strains. The best LLA producer strain, A. brasiliensis BRFM1877, integrated 6 ldhA gene copies in its genome and demonstrated an intracellular LDH activity of $9.2 \times 10^{-2} \mathrm{U} / \mathrm{mg}$. Switching the nitrogen source from ammonium sulfate to Na-nitrate prevented a strong drop in $\mathrm{pH}$ and increased the L-LA conversion yields. With nitrate, at $\mathrm{pH} \mathrm{3,} \mathrm{L-LA} \mathrm{conversion}$ yield reached $44 \%(\mathrm{w} / \mathrm{w})$ with low quantities of byproduct. L-LA productivity was higher at near-neutral $\mathrm{pH}$ than at $\mathrm{pH} 3$, but the lower $\mathrm{pH}$ prevents the production of gluconic acid resulting in similar L-LA conversion yields with or without $\mathrm{pH}$ neutralization. The recombinant strain was able to produce L-LA from xylose and associated arabinose, the main pentose monomers found in plant biomass. It was also able to produce L-LA directly from starch and birchwood xylan without addition of polysaccharide depolymerizing enzyme cocktails. Further studies including process and metabolic engineering are expected to increase both titer and yield. These findings raise new prospects for using Aspergillus species as new hosts for L-LA production from plant biomass.

\section{Material and methods \\ Microbial strains}

Escherichia coli JM109 (Promega, Charbonnière, France) was used as a host for the cloning and propagation of vectors. A wild-type A. brasiliensis strain (BRFM103, CIRMCF, Marseille, France) collected in a temperate forest was used as host for fungal transformation [33]. The eight recombinant L-LA-producing strains were registered in the CIRM as BRFM1872, BRFM1873, BRFM1874, BRFM1875, BRFM1877, BRFM1879, BRFM1880, BRFM1881.

\section{Media and culture conditions}

A. brasiliensis strains were maintained on agar solidified minimal medium $(\mathrm{MM})$ containing $10 \mathrm{~g} / \mathrm{L} \mathrm{D}$-glucose,

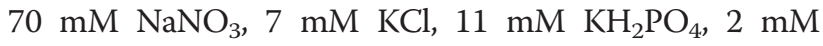


$\mathrm{MgSO}_{4}$, agar $16 \mathrm{~g} / \mathrm{L}$ and trace elements $\left(76 \mu \mathrm{M} \mathrm{ZnSO}_{4}\right.$, $178 \mu \mathrm{M} \mathrm{H}_{3} \mathrm{BO}_{3}, 25 \mu \mathrm{M} \mathrm{MnCl}, 18 \mu \mathrm{M} \mathrm{FeSO}, 7.1 \mu \mathrm{M}$ $\mathrm{CoCl}_{2}, 6.4 \mu \mathrm{M} \mathrm{CuSO}_{4}, 6.2 \mu \mathrm{M} \mathrm{Na}_{2} \mathrm{MoO}_{4}, 174 \mu \mathrm{M}$ EDTA$\mathrm{Na}_{2}$ ). All medium components were from Prolabo except the Na-nitrate which was purchased from by SigmaAldrich.

After transformation of the parental strain, the transformants were grown on selective solid MM medium supplemented with 10 or $20 \mu \mathrm{g} / \mathrm{mL}$ hygromycin B (Sigma-Aldrich). All solid cultures were incubated at $30^{\circ} \mathrm{C}$.

Liquid cultures were carried out in $250-\mathrm{mL}$ flasks containing $100 \mathrm{~mL}$ liquid medium MM1 or MM2. MM1 contained $76 \mathrm{mM}\left(\mathrm{NH}_{4}\right)_{2} \mathrm{SO}_{4}$ (Sigma-Aldrich), $1 \mathrm{mM} \mathrm{CaCl}$, $11 \mathrm{mM} \mathrm{KH} \mathrm{PO}_{4}, 2 \mathrm{mM} \mathrm{MgSO} 4,50 \mathrm{~g} / \mathrm{L}$ D-glucose and trace elements. In MM2, 151.4 mM of $\mathrm{NaNO}_{3}$ was used as nitrogen source instead of $\left(\mathrm{NH}_{4}\right)_{2} \mathrm{SO}_{4}$ in order to minimize the impact of $\left(\mathrm{NH}_{4}\right)_{2} \mathrm{SO}_{4}$ consumption on $\mathrm{pH}$ acidification. Different carbon sources were used in MM2, at $50 \mathrm{~g} / \mathrm{L}$ : D-glucose, D-xylose (Sigma-Aldrich), L-arabinose (Sigma-Aldrich), potato starch (Fluka, Sigma-Aldrich) and birchwood xylan (Sigma-Aldrich). When stated, an extra $20 \mathrm{~g} / \mathrm{L}$ glucose was added to the medium at $96 \mathrm{~h}$ of culture. For experiments with added $\mathrm{CaCO}_{3}, 8 \mathrm{~g}$ of sterilized $\mathrm{CaCO}_{3}$ was added to the cultures after $24 \mathrm{~h}$.

Liquid culture media were inoculated with $10^{6}$ spores/ $\mathrm{mL}$. To avoid germination problems in MM2 liquid medium containing pentose monomers and complex substrates, culture media were inoculated using $1 \mathrm{~mL}$ of mycelium from a $24 \mathrm{~h}$ preculture in Sabouraud broth.

Liquid cultures were incubated at $30^{\circ} \mathrm{C}$ under shaking at $140 \mathrm{rpm}$ (50 $\mathrm{mm}$ orbital).

Expression vector construction and fungal transformation The $l d h A$ (lactate dehydrogenase A gene) sequence of $R$. oryzae (Genbank accession number AF226154) was codon-optimized for expression in Aspergillus and synthesized by Life Technologies. The construct contained a NcoI and HindIII at the $5^{\prime}$ and $3^{\prime}$ ends, respectively, for cloning into pAN52.3 (kindly supplied by Pr. P. J. Punt, TNO, The Netherlands). The recombinant gene inserted into the expression vector was sequence-checked before transformation. Fungal co-transformation of A. brasiliensis BRFM103 was carried out as previously described [44] using pAN52.3 ldhA vector and pAN7.1 co-vector (kindly supplied by Pr. P. J. Punt, TNO, The Netherlands). The pAN7.1 co-vector contained the hph selection marker conferring hygromycin B resistance. Hygromycin B inhibition tests were carried out with the wild-type A. brasiliensis BRFM103 strain grown on MM solid medium supplemented with $10,30,50,75,100,150,200,300$, and $400 \mu \mathrm{g} / \mathrm{mL}$ hygromycin B (Sigma Aldrich) inoculated with spore suspensions. Growth inhibition tests showed that low hygromycin B concentration $(10 \mu \mathrm{g} / \mathrm{mL})$ slowed fungal growth and higher (above $10 \mu \mathrm{g} / \mathrm{mL}$ ) hygromycin B concentrations prevented growth. Transformant screening was therefore done on MM solid medium supplemented with $20 \mu \mathrm{g} / \mathrm{mL}$ of hygromycin B.

\section{Organic acid production and sugar consumption}

Samples were taken from the liquid screening medium during the incubation, and mycelia were removed by centrifugation. The $\mathrm{pH}$ values of the supernatants were determined with an Inolab $\mathrm{pH} 1$ Level 1 electrode (WTW, Weilheim, Germany).

For transformant screening, L-LA was detected spectrometrically by measuring ABTS oxidation at $420 \mathrm{~nm}$ as previously described [45]. The reaction mix contained ABTS $0.5 \mathrm{mM}$, HRP $(1.5 \mathrm{mM})$ and $1.5 \mathrm{mM}$ lactate oxidase in $1 \mathrm{M}$ phosphate buffer $\mathrm{pH} 6$.

The culture supernatants of L-LA-producing strains were analyzed by HPLC (Agilent 1100 series HPLC or Dionex Ultimate 3000 series, ThermoScientific) for organic acids and sugars using an Aminex HPX-87H Organic Acid Analysis Column $(100 \mathrm{~mm} \times 7.8 \mathrm{~mm}$, Biorad, Marne-la-Coquette, France). The column was equilibrated in $2.5 \mathrm{mM} \mathrm{H}_{2} \mathrm{SO}_{4}$ in water at 35 or $30^{\circ} \mathrm{C}$, and samples were eluted with $2.5 \mathrm{mM} \mathrm{H}_{2} \mathrm{SO}_{4}$ at a $0.6 \mathrm{~mL} / \mathrm{min}$ flow rate. Sugars and ethanol were detected with a differential refractometer (HP1047A Hewlett Packard or Dionex Ultimate 3000 RI detector, Thermoscientific). Organic acids were detected with a UV detector (Agilent 1100 series wavelength detector or Dionex Ultimate 3000 series RS variable wavelength detector, ThermoScientific). Data were acquired using ChemStation (Agilent, Hewlett Packard) or Chromeleon (Dionex, Thermoscientific) software.

\section{Dry biomass determination}

Dry biomass was determined by gravimetric method. At the end of the culture, the biomass was collected onto nylon filters (Miracloth, pore size of 22-25 $\mu \mathrm{m}$ ) and washed with $200 \mathrm{~mL}$ distilled water to remove residual media. Washed biomass was then oven-dried at $105^{\circ} \mathrm{C}$ until a constant weight was reached (approximately $48 \mathrm{~h}$ ).

\section{Determination of IdhA gene copy numbers and intracellular LDH activity}

ldhA gene copy numbers in A. brasiliensis-ldhA strains were determined by quantitative real-time PCR (qPCR). Mycelia were harvested at $24 \mathrm{~h}$ of culture onto a nylon filter and washed with $100 \mathrm{~mL}$ distilled water. For each strain, $100 \mathrm{mg}$ of mycelium was ground down (Fast prep- $24^{\circ}$, MP Biomedicals), and genomic DNA was extracted using a Nucleospin Plant II kit (Macherey-Nagel, Germany). Concentration and purity of genomic DNA were determined by UV detection using a Nanodrop ${ }^{\circledR}$ spectrometer (Nanodrop2000c, Thermoscientific). Genomic DNA was considered pure enough when $A_{260 / 280}$ 
and $\mathrm{A}_{260 / 230}$ were above 1.8 and 1.6, respectively. Monocopy Translation Elongation Factor $1 \alpha($ tefl $\alpha)$ and RNA Binding Protein 1 ( $r b p 1)$ genes were selected as internal calibrator and internal control, respectively. Specific primers for $l d h A$ (forward: 5' -GATAAGACCGCCATCTC CAA-3'; reverse: 5'-CTTCTCGACGTAGACGG-3'), ef $1 \alpha$ (forward 5'-AGGTCATCGTCCTCAACCAC-3'; reverse $5^{\prime}$-TGGGGGAAGATTCAACAGAC-3') and rbp1 (forward: 5'-CCGAAGGCTATGCAGAAGTC-3'; reverse: 5' -AGACAAGTTGGGGTCACCAG-3') were designed using Primer3 [46]. Amplification efficiencies were determined using 4 serial dilutions of genomic DNA ranging from 1 to $1.10^{-3} \mathrm{ng} / \mu \mathrm{L}$, and primers were validated. Each reaction mix comprised $2 \mu \mathrm{L}$ genomic DNA $(1 \mathrm{ng} / \mu \mathrm{L})$, $0.3 \mu \mathrm{L}$ forward and reverse primers $(10 \mu \mathrm{M}$ each) and $5 \mu \mathrm{L}$ Sso AdvancedTM SYBR ${ }^{\circ}$ Green Supermix (Bio-Rad, United States). The qPCR reactions were performed in technical duplicates on a CFX96 Touch Real-Time PCR Detection System (Bio-Rad) at $95^{\circ} \mathrm{C}$ for $30 \mathrm{sec}$, then 40 cycles at $95^{\circ} \mathrm{C}$ for $5 \mathrm{sec}$ and $58^{\circ} \mathrm{C}$ for $5 \mathrm{sec}$. Melting curve analysis was performed after the PCR to verify the Tm of the amplicons. Gene copy numbers of $l d h A$ and $r b p 1$ were calculated relative to tefl $\alpha$ by the $\Delta \mathrm{Ct}$ method using the amplification efficiency of each analyzed gene. $r b p 1$ gene copy number needs to be 1 in order to validate the qPCR run.

For intracellular LDH activity, mycelia were harvested at $72 \mathrm{~h}$ of culture onto a nylon filter and washed with $100 \mathrm{~mL}$ of MOPS buffer $\mathrm{pH} 7.2$. The mycelia were stored at $-80^{\circ} \mathrm{C}$ until grinding in liquid nitrogen using a Freezer Mill ${ }^{\circ} 6770$ (SPEX Sample Prep; Metuchen, NJ), then 200-300 mg of frozen mycelia powder was aliquoted into $2 \mathrm{~mL}$ tubes and suspended in extraction buffer (MOPS $1 \mathrm{M}, 10 \%$ glycerol, $1 \mathrm{mM}$ DTT, pH 7.2), 20\% w/v. Samples were centrifuged at $14,500 \mathrm{~g}$ for $5 \mathrm{~min}$ at $4^{\circ} \mathrm{C}$. NADH reductive activities in the supernatants were determined spectrophotometrically $\left(\mathrm{A}_{340 \mathrm{~nm}}\right)$ by measuring the kinetics of $\mathrm{NADH}, \mathrm{H}^{+}$reduction (Sigma-Aldrich, $175 \mu \mathrm{M}$ ) with and without pyruvate (Sigma-Aldrich, $40 \mathrm{mM}$ ) in $1 \mathrm{M}$ MES buffer, $\mathrm{pH}$ 6.8. For each supernatant, the difference between $\mathrm{NADH}, \mathrm{H}^{+}$reductive activity with and without pyruvate was associated to combined LDH activity plus alcohol dehydrogenase $(\mathrm{ADH})$ activity. Total protein concentrations were determined using the Bradford method. NADH reductive activities were expressed in Units $(\mathrm{U})$ per $\mathrm{mg}$ of protein, where one $U$ was defined as the amount of $\mu$ mole $\mathrm{NADH}, \mathrm{H}^{+}$reduced by the $\mathrm{LDH}$ (or ADH) per minute. $\mathrm{NADH}$ reductive activities were measured in triplicate. Since the wild-type strain did not produce L-LA but ethanol, in vitro NADH consumption in this strain was attributed to the action of pyruvate decarboxylase and ADH. The LDH dehydrogenase activity of the transformants was therefore obtained by subtracting the NADH dehydrogenase activity of the wild-type strain from the total NADH dehydrogenase activity of each transformant.

\section{Abbreviations}

ADH: Alcohol dehydrogenase; $h p h$ : Hygromycin B phosphotransferase gene; L-LA: L-lactic acid; LDH: Lactate dehydrogenase enzyme; MM: Minimum medium; pdc: Pyruvate decarboxylase gene; IdhA: Lactate dehydrogenase gene (from R. oryzae); tef1a: Translation elongation factor 1a gene; rpb1: RNA polymerase II large subunit gene.

\section{Competing interests}

The authors declare that they have no competing interests.

\section{Authors' contributions}

$\mathrm{NL}$ participated in the design of the study, carried out the experiments, analyzed the results and drafted the manuscript. MNR conceived the gene copy number study, analyzed the results, and drafted the manuscript. NF and SR participated in the study, analyzed the results and drafted the manuscript. AL conceived and designed the molecular studies, analyzed the results, coordinated the study and drafted the manuscript. NL, NF, SC, IHG, JCS, SR, AL conceived the study. All authors have read and approved the final manuscript.

\section{Acknowledgements}

This work was supported by an Industrial Training and Research Agreement (CIFRE) and co-funded by the National Association of Research and Technology (ANRT). The authors thank David Martina for his help with strain culturing and analysis and Chloé Bennati-Granier for her advice on substrate preparation. We thank Dr. P.J. Punt and Prof. C.A.M.J.J. van den Hondel (TNO, Zeist, The

Netherlands) for providing the fungal expression plasmids.

\section{Author details}

'INRA, UMR1163 Biodiversité et Biotechnologie Fongiques, Polytech' Marseille, 163 avenue de Luminy, CP 925, 13288, Marseille Cedex 09, France. ${ }^{2}$ Aix-Marseille Université, UMR1 163 Biodiversité et Biotechnologie Fongiques, Polytech' Marseille, 163 avenue de Luminy, CP 925, 13288, Marseille Cedex 09, France. ${ }^{3}$ ARD Agro-Industrie Recherche et Développement, Route de Bazancourt, 51110, Pomacle, France. ${ }^{4}$ Aix-Marseille Université, Unité de Recherche sur les Maladies Infectieuses et Tropicales Emergentes (URMITE), UM63, CNRS 7278, IRD 198, INSERM U1095, IHU Méditerranée Infection, Pôle des Maladies Infectieuses, Assistance Publique-Hôpitaux de Marseille, Faculté de Médecine, 27 Bd Jean Moulin, 13005 Marseille, France.

Received: 5 January 2015 Accepted: 23 April 2015

Published online: 03 May 2015

\section{References}

1. Vijayakumar J, Aravindan R, Viruthagiri T. Recent trends in the production, purification and application of lactic acid. Chem Biochem Eng Q. 2008;22:245-64

2. Miller C, Fosmer A, Rush B, Mc Mullin T, Beacom D, Suominen P. Industrial production of lactic acid. Compr Biotechnol. 2011;3:179-88.

3. Wee Y-J, Kim J-N, Ryu H-W. Biotechnological production of lactic acid and its recent applications. Food Technol Biotechnol. 2006:44:163-72.

4. Jem KJ, van der Pol JF, de Vos S. Microbial lactic acid, its polymer poly(lactic acid), and their industrial applications. In: Chen GG-Q, editor. Plastic from Bacteria. Volume 14. Berlin, Heidelberg: Springer Berlin Heidelberg; 2010. p. 323-46. Microbiology Monographs.

5. Hofvendahl K, Hahn-Hägerdal B. Factors affecting the fermentative lactic acid production from renewable resources. Enzyme Microb Technol. 2000;26:87-107.

6. Taskila $\mathrm{S}, \mathrm{Ojamo} \mathrm{H}$. The current status and future expectations in industrial production of lactic acid by lactic acid bacteria. In: Kongo M, editor. Lactic Acid Bacteria - R \& D for Food, Health and Livestock Purposes. Rijeka, Croatia: Tech Open Access Publisher; 2013. p. 615-32.

7. Colombié S, Dequin S, Sablayrolles J. Control of lactate production by Saccharomyces cerevisiae expressing a bacterial LDH gene. Enzyme Microb Technol. 2003;33:38-46.

8. Ishida N, Saitoh S, Tokuhiro K, Nagamori E, Matsuyama T, Kitamoto K, et al. Efficient production of I-lactic acid by metabolically engineered Saccharomyces cerevisiae with a genome-integrated I-lactate dehydrogenase gene. Appl Environ Microbiol. 2005;71:1964-70. 
9. Saitoh S, Ishida N, Onishi T, Tokuhiro K, Nagamori E, Kitamoto K, et al. Genetically engineered wine yeast produces a high concentration of L-lactic acid of extremely high optical purity. Appl Environ Microbiol. 2005;71:2789-92.

10. Skory CD. Lactic acid production by Saccharomyces cerevisiae expressing a Rhizopus oryzae lactate dehydrogenase gene. J Ind Microbiol Biotechnol. 2003;30:22-7.

11. Valli M, Sauer M, Branduardi P, Borth N, Porro D, Mattanovich D. Improvement of lactic acid production in Saccharomyces cerevisiae by cell sorting for high intracellular pH. Appl Environ Microbiol. 2006;72:5492-9.

12. Bianchi MM, Brambilla L, Protani F, Liu CL, Lievense J, Porro D. Efficient homolactic fermentation by Kluyveromyces lactis strains defective in pyruvate utilization and transformed with the heterologous LDH gene. Appl Environ Microbiol. 2001;67:5621-5.

13. Ilmén M, Koivuranta K, Ruohonen L, Rajgarhia V, Suominen P, Penttilä M. Production of L-lactic acid by the yeast Candida sonorensis expressing heterologous bacterial and fungal lactate dehydrogenases. Microb Cell Fact. 2013;12:53.

14. Osawa F, Fujii T, Nishida T, Tada N, Ohnishi T, Kobayashi O, et al. Efficient production of L-lactic acid by Crabtree-negative yeast Candida boidinii. Yeast. 2009;26:485-96.

15. Koivuranta KT, Ilmén M, Wiebe $M G$, Ruohonen L, Suominen P, Penttilä M L-lactic acid production from D-xylose with Candida sonorensis expressing a heterologous lactate dehydrogenase encoding gene. Microb Cell Fact. 2014;13:107

16. Gírio FM, Fonseca C, Carvalheiro F, Duarte LC, Marques S, Bogel-Łukasik R. Hemicelluloses for fuel ethanol: a review. Bioresour Technol. 2010;101:4775-800

17. Garcia Sanchez R, Karhumaa K, Fonseca C, Sànchez Nogué V, Almeida JR, Larsson CU, et al. Improved xylose and arabinose utilization by an industrial recombinant Saccharomyces cerevisiae strain using evolutionary engineering. Biotechnol Biofuels. 2010;3:13.

18. IImén $M$, Koivuranta $K$, Ruohonen L, Suominen $P$, Penttilä M. Efficient production of L-lactic acid from xylose by Pichia stipitis. Appl Environ Microbiol. 2007;73:117-23.

19. Hasunuma T, Okazaki F, Okai N, Hara KY, Ishii J, Kondo A. A review of enzymes and microbes for lignocellulosic biorefinery and the possibility of their application to consolidated bioprocessing technology. Bioresour Technol. 2013;135:513-22.

20. Sánchez C. Lignocellulosic residues: biodegradation and bioconversion by fungi. Biotechnol Adv. 2009;27:185-94.

21. Soccol CR, Stonoga VI, Raimbault M. Production of L-lactic acid by Rhizopus species. World J Microbiol Biotechnol. 1994;10:433-5.

22. Mudaliyar P, Chandrashekar K. Screening of novel substrates for lactic acid production by Rhizopus oryzae. Int J Life Sci Pharma Rev. 2012;2:128-33.

23. Zhang ZY, Jin B, Kelly JM. Production of lactic acid from renewable materials by Rhizopus fungi. Biochem Eng J. 2007;35:251-63.

24. Magnuson JK, Lasure LL. Organic Acid Production by Filamentous Fungi. In: Tkacz JS, Lange L, editors. Advances in Fungal Biotechnology for Industry, Agriculture, and Medicine. Boston: MA: Springer US; 2004. p. 307-40

25. Tay A, Yang S-T. Production of $L(+)$-lactic acid from glucose and starch by immobilized cells of Rhizopus oryzae in a rotating fibrous bed bioreactor. Biotechnol Bioeng. 2002;80:1-12.

26. Maas RHW, Bakker RR, Eggink G, Weusthuis RA. Lactic acid production from xylose by the fungus Rhizopus oryzae. Appl Microbiol Biotechnol. 2006;72:861-8.

27. Saito K, Hasa Y, Abe H. Production of lactic acid from xylose and wheat straw by Rhizopus oryzae. J Biosci Bioeng. 2012;114:166-9.

28. Vially G, Marchal R, Guilbert N. L(+) Lactate production from carbohydrates and lignocellulosic materials by Rhizopus oryzae UMIP 4.77. World J Microbiol Biotechnol. 2009;26:607-14.

29. Park EY, Anh PN, Okuda N. Bioconversion of waste office paper to $L(+)$-lactic acid by the filamentous fungus Rhizopus oryzae. Bioresour Technol. 2004:93:77-83.

30. De Vries RP. Regulation of Aspergillus genes encoding plant cell wall polysaccharide-degrading enzymes; relevance for industrial production. Appl Microbiol Biotechnol. 2003;61:10-20.

31. Varga J, Kocsubé S, Tóth B, Frisvad JC, Perrone G, Susca A, et al. Aspergillus brasiliensis sp. nov., a biseriate black Aspergillus species with world-wide distribution. Int J Syst Evol Microbiol. 2007;57:1925-32.

32. Frisvad JC, Larsen TO, Thrane U, Meijer M, Varga J, Samson RA, et al. Fumonisin and ochratoxin production in industrial Aspergillus niger strains. PLoS One. 2011;6:e23496.
33. Liaud N, Giniés C, Navarro D, Fabre N, Crapart S, Gimbert I, et al. Exploring fungal biodiversity: organic acid production by 66 strains of filamentous fungi. Fungal Biol Biotechnol. 2014;1:1

34. Ishida N, Saitoh S, Onishi T, Tokuhiro K, Nagamori E, Kitamoto K, et al. The effect of pyruvate decarboxylase gene knockout in Saccharomyces cerevisiae on L-lactic acid production. Biosci Biotechnol Biochem. 2006;70:1148-53.

35. Ida Y, Furusawa C, Hirasawa T, Shimizu H. Stable disruption of ethanol production by deletion of the genes encoding alcohol dehydrogenase isozymes in Saccharomyces cerevisiae. J Biosci Bioeng. 2012;113:192-5.

36. Cogoni C, Macino G. Homology-dependent gene silencing in plants and fungi: a number of variations on the same theme. Curr Opin Microbiol. 1999;2:657-62.

37. Lubertozzi D, Keasling JD. Developing Aspergillus as a host for heterologous expression. Biotechnol Adv. 2009;27:53-75.

38. Kubicek CP, Punt P, Visser J. Production of organic acids by filamentous fungi. In: Hofrichter M, editor. Industrial Applications. Berlin, Heidelberg: Springer Berlin Heidelberg; 2011. p. 215-34.

39. Ishida N, Saitoh S, Ohnishi T, Tokuhiro K, Nagamori E, Kitamoto K, et al. Metabolic engineering of Saccharomyces cerevisiae for efficient production of pure L-(+)-lactic acid. Appl Biochem Biotechnol. 2006;131:795-807.

40. Skory CD. Lactic acid production by Rhizopus oryzae transformants with modified lactate dehydrogenase activity. Appl Microbiol Biotechnol. 2004;64:237-42.

41. Branduardi P, Sauer M, De Gioia L, Zampella G, Valli M, Mattanovich D, et al. Lactate production yield from engineered yeasts is dependent from the host background, the lactate dehydrogenase source and the lactate export. Microb Cell Fact. 2006;5:4.

42. Verho R, Londesborough J, Penttila M, Richard P. Engineering redox cofactor regeneration for improved pentose fermentation in Saccharomyces cerevisiae. Appl Environ Microbiol. 2003;69:5892-7.

43. Witteveen CFB, Busink R, Van De Vondervoort P, Dijkema C, Swart K, Visser J. L-Arabinose and D-Xylose catabolism in Aspergillus niger. Microbiology. 1989;135:2163-71.

44. Punt $P$, van den Hondel $C$. Transformation of filamentous fungi based on hygromycin B and phleomycin resistance markers. Methods Enzymol. 1992;216:447-57

45. Liaud N, Navarro D, Vidal N, Sigoillot J-C, Raouche S. High throughput automated colorimetric method for the screening of L-lactic acid producing microorganisms. MethodsX. 2014;1:254-7.

46. Untergrasser A, Cutcutache I, Koressaar T, Ye J, Faircloth B, Rozen S. Primer 3-new capabilities and interfaces. Nucleic Acids Res. 2012;40:e115.

\section{Submit your next manuscript to BioMed Central and take full advantage of:}

- Convenient online submission

- Thorough peer review

- No space constraints or color figure charges

- Immediate publication on acceptance

- Inclusion in PubMed, CAS, Scopus and Google Scholar

- Research which is freely available for redistribution 